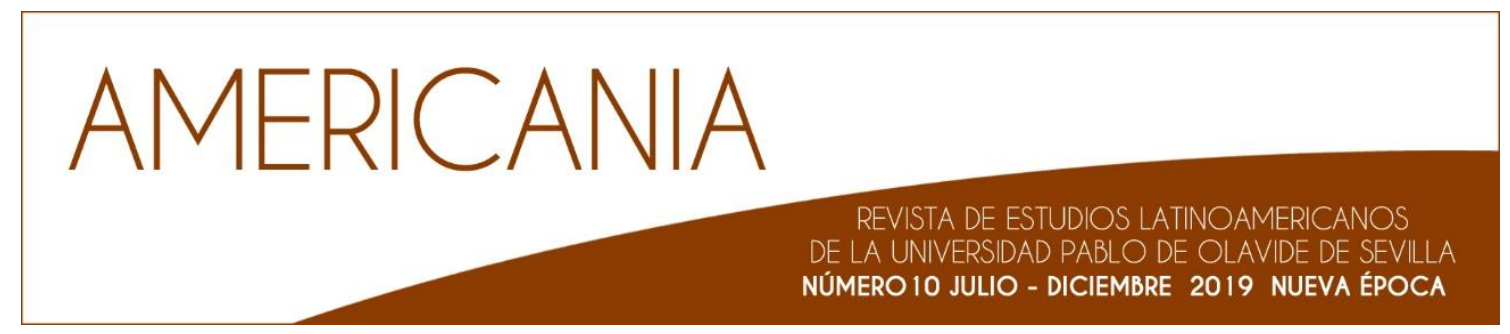

\title{
YARAVIIES QUITEÑOS
}

\section{Una colección de piezas musicales que suenan desde el pasado}

\section{Resumen}

En 1865 llegó a Quito una comisión científica española en la que figuraba Marcos Jiménez de la Espada. En su visita se interesó por registrar los cantos, danzas y ritmos populares de la región, pidiendo que se le enviara una colección de piezas musicales tradicionales para el Museo de Ciencias Naturales de Madrid. Juan Agustín Guerrero, músico quiteño, después de una profunda investigación y ardua dedicación, transcribió varias melodías y se las envió a Jiménez de la Espada, quien las presentó en Madrid, con el título Yaravíes Quiteños, en el Cuarto Congreso Internacional de Americanistas en 1881, quedando una copia manuscrita de esta obra y sus partituras en la Biblioteca Nacional de Madrid.

\section{Palabras Clave}

Juan Agustín Guerrero - Comisión Científica del Pacífico - Música tradicional - Quito - Siglo XIX

Máster en Historia de América Latina. Mundos Indígenas, Universidad Pablo de Olavide (2016). Doctorando en el Programa de Doctorado en Historia y Estudios Humanísticos: Europa, América, Arte y Lenguas, de la línea de Historia de América. Realiza su tesis sobre la música colonial en los conventos de Ibarra y Quito. 


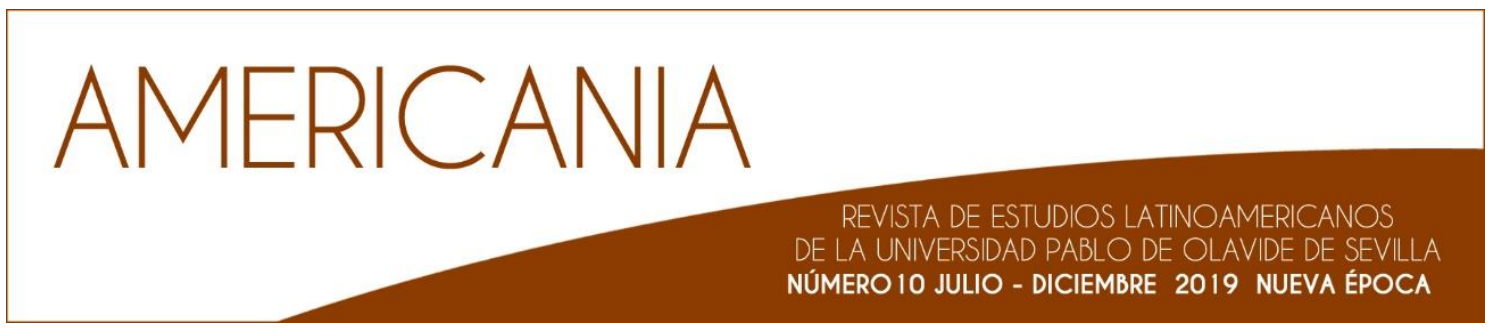

\title{
YARAVIES QUITEÑOS
}

\section{A collection of musical pieces that sounds from the past}

\begin{abstract}
In 1865 Marcos Jiménez de la Espada arrived in Quito as a member of a Spanish scientific commission. During his visit, he was interested in registering the popular songs, dances and rhythms of the region, requesting a collection of traditional musical pieces to be sent to the Museum of Natural Sciences in Madrid. Juan Agustín Guerrero, a musician from Quito, after an arduous investigation, transcribed several melodies and sent them to Jiménez de la Espada, who presented them in Madrid, under the title Yaravíes Quiteños, at the Fourth International Congress of Americanists in 1881, leaving a manuscript copy of this work and its scores in the National Library of Madrid.
\end{abstract}

\section{Key Words}

Juan Agustín Guerrero - Pacific Cientific Comisision - Traditional music - Quito - $19^{\text {th }}$ Century 


\section{Introducción}

Marcos Jiménez de la Espada (Cartagena - España, 1831), biólogo, geógrafo y americanista, participó con poco más de treinta años de edad en la famosa expedición denominada Comisión Científica del Pacífico (1862-1865), una apasionante travesía que le llevó a recorrer buena parte del continente americano, incluyendo las regiones y ciudades de Guayaquil y Quito, y cuya bibliografía es tan amplia que no habría espacio aquí para citarla, ni es el caso. El escritor peruano Ricardo Palma² recordaba cómo lo conoció cuando Jiménez de la Espada pasó por Lima, una noche de invierno en la redacción del periódico limeño El Mercurio. Su director, don Atanasio Fuentes ('el murciélago'), los presentó: “...llego un joven con mucha gallardía con una elegante capa española...".3

La Comisión Científica estaba integrada en origen, aparte de por Jiménez de la Espada, por Patricio Paz y Membiela (presidente), Fernando Amor (jefe científico), Francisco de Paula Martínez (naturalista, cronista y secretario), Manuel Almagro y Vega (etnógrafo y antropólogo), Juan Isern (botánico), Rafael Castro (dibujantefotógrafo) y Bartolomé Puig (taxidermista) ${ }^{4}$. De estos, por varias vicisitudes, quedaron al final solamente cuatro: Marcos Jiménez de la Espada, Francisco de Paula Martínez, Manuel Almagro y Juan Isern5, quienes realizaron el viaje de regreso a España, en mitad de mil y una vicisitudes y tribulaciones, por la ruta de río Amazonas entre 1864 y 1865.

A su regreso a España, Jiménez de la Espada demostró haberse convertido en un gran americanista, recopilando documentos, crónicas y relatos. En 1892 había escrito ya más de cuarenta libros sobre el Perúb. Podemos igualar su pensamiento con los de William H. Prescott o Enrique de Vedia, al opinar, con demasiada emoción, que la Conquista del Perú fue "... uno de los monumentos históricos más bellos ... (quizá el primero) ..."7.

Una de las obras que publicó fueron las Noticias auténticas del río Marañón, donde desgrana con lujo de detalles el viaje realizado por el Padre Pablo Maroni y la

Palma, Ricardo, Tradiciones y artículos históricos, Imp. Torres Aguirre, Lima, 1899, 110.

Ibid., 114.

Jiménez de la Espada, Marcos; Martínez, Francisco de Paula; Almagro, Manuel; Isern, Juan, El Gran Viaje, Ediciones Abya-Yala, Quito, 1998, 5-6.

Ibid.

Ibid., 115.

Cieza de León, Pedro de; Jiménez de la Espada, Marcos (pub.), Tercero Libro de las guerras civiles del Perú el cual se Ilama La Guerra de Quito, Imp. M. G. Hernández, Madrid, 1877, VII. 
misión jesuítica que empezó en 17298, a partir del único manuscrito conservado en la Real Academia de Historia de Madrid9. Jiménez de la Espada contrastó muchos detalles de la vida del Padre Maroni con la Historia Moderna del Reino de Quito, del P. Juan de Velasco (jesuita riobambeño)10, lo cual demuestra su gusto por las relecturas, comparaciones y revisiones. Y a todo se dedicó con especial ahínco. No en vano, solía decir que "la ciencia también es milicia"1 1 .

Cuando alcanzaron el puerto de Guayaquil, partieron hacia el interior del continente en el vapor Washington por el rio Guayas hasta Babahoyo, poblado de Bodegas, donde descansaron para preparar la ascensión a la Sierra12. Atravesando Chima, San Miguel y San José de Chimbo, se detuvieron en Guaranda, donde admiraron el gran Chimborazo 13. Continuaron por Mocha, por las faldas del Cariguairazo llegando a Ambato ${ }^{14}$. En el trayecto divisaron los dos grande volcanes de Cotopaxi y Tungurahua. En Latacunga se les reveló la cima del Yanaurco y la montaña Rumiñahui15, visitaron la hacienda El Gallo (ruinas de un palacio inca), lvego Rumipamba ${ }^{16}$ y en Machachi contemplaron los nevados Corazón, Illinizas y Pichincha 17.

Al llegar a Quito se alojaron en el Hotel Americano, situado en la plaza de San Agustín. Visitaron al presidente Gabriel García Moreno, quien les apoyó para que realizaran varias ascensiones a nevados ${ }^{18}$. Por otra parte, Jiménez de la Espada estableció buenas relaciones con William Jameson, un inglés profesor de botánica y química en la Universidad de los jesuitas de Quito 19, así como con el geógrafo ecuatoriano Manuel Villavicencio, quien poseía una quinta situada en las faldas del cerro del Panecillo, que domina la ciudad (allí Jiménez de la Espada había

8 Jiménez de la Espada, Marcos, Noticias auténticas del famoso río Marañón, Imp. Real Academia de la Historia, Madrid, 1889, 9.

9 Real Academia de Historia de Madrid, legajo 7, grada 4ạa, estante 17. Jiménez de la Espada era conocedor de abundantes referentes históricos, como el desconocido Diccionario inédito, de Antonio de Alcedo. Ibid, 14.

10 No la compara con la edición impresa de 1842, sino con el manuscrito original del autor, que es más completo. Ibid, 8.

11 Palma, Ricardo, Tradiciones..., 115.

12 Ibid., 22-23.

13 Ibid., 31-34.

14 Ibid., 38-40.

15 Ibid., 41-42.

16 Ibid., 45-46.

17 Ibid., 46-47.

18 Ibid., 49-50.

19 Ibid., 11. 
improvisado un invernadero para conservar varios ejemplares de plantas traídas del oriente ecuatoriano20).

Jiménez fue recogiendo, con sumo detalle, la flora y su paisaje, sin descuidar a la sociedad ecuatoriana y sus costumbres, interesándose de manera muy especial por la música. Así fue como contactó con Juan Agustín Guerrero (Quito - Ecuador, 1818)21, un compositor, pianista, profesor de música, musicólogo, poeta, pintor, crítico y caricaturista (ver Fig. 1)22, a quien pidió que le recopilase melodías "indianas y populares" de la provincia para llevarlas al Museo de Ciencias Naturales de Madrid23.

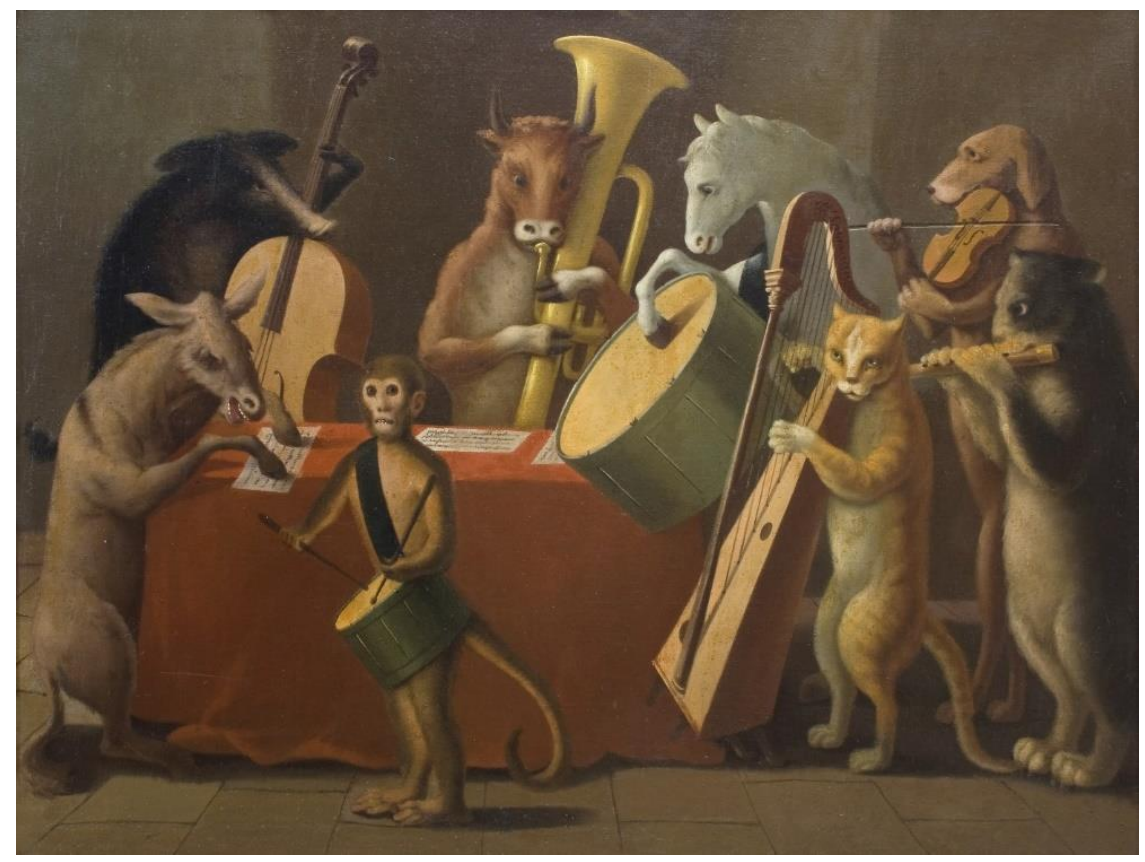

Figura 1 Juan Agustín Guerrero, El club estrafalario, óleo sobre lienzo, Siglo XIX. Colección Nacional, Quito. Colección Arte Moderno. Ministerio de Cultura y Patrimonio de Quito-Ecuador.

En Quito, los encargados de la enseñanza musical habían sido siempre los organistas, manteniendo el estilo antiguo de adiestramiento, en base a los 'modos', 'tonos' y el 'bajo continuo'. En cambio, los métodos de enseñanza de Juan Agustín Guerrero serían una novedad en la ciudad, difundiendo los fundamentos de la armonía tonal-funcional (estilo introducido en Quito por el español Manuel Zaporta,

20 Ibid. y cit., 19

21 León Mera, Juan, Cantares del pueblo, Banco Central del Ecuador, Quito, 15. Cit: Guerrero, Juan Agustín, Yaravíes Quiteños, música ecuatoriana del siglo XIX, Archivo sonoro del municipio de Quito, Quito, 1993, 3.

22 Ibid.

23 Guerrero, Juan Agustín, Imágenes del Ecuador del siglo XIX, Espasa Calpe, Madrid, 1981, 21. 
maestro de Guerrero ${ }^{24}$ ). En su Catecismo musical25 expone estos nuevos conceptos, "en términos sencillos para que estuvieran al alcance aún de los niños..."26. Ahí aparecen temas como claves, líneas de pentagrama, notas musicales, silencios, accidentes, ligaduras, tiempos, compases, intervalos, armaduras, dinámica, agógica, conceptos de armonía, inversiones e indicaciones de expresión. A continuación publicó su Curso elemental de música ${ }^{27}$, donde profundizaba en la 'composición', enseñando modelos temáticos, cadencias, tipos de frases, tipos de modulación, instrumentación y formación de las voces corales. Estos, junto al libro de historia La música ecuatoriana desde su origen hasta 1875, son el referente musical más importante del siglo XIX en la capital ecuatoriana y, en general, en toda la república del Ecuador.

Atendiendo al pedido de Jiménez de la Espada, Guerrero inició la recopilación de piezas musicales, reproduciendo 'de oído' las interpretaciones de músicos no profesionales, y ejecutadas con pingullo, rondador, arpa o guitarra, en localidades o haciendas que habría visitado por los alrededores de Quito, llegando hasta Otavalo. En la transcripción que utilizó, eligió escribirlas en dos claves (sol y fa), sin indicar instrumentación alguna.

Al ser este un ejercicio tan dificultoso, podríamos decir que la recopilación (de la primera parte) es más bien un 'boceto musical', una muestra. Por esto pensamos que estas piezas debieron tener más variantes en lo melódico, armónico y rítmico, y así entendemos también que la inscripción que anotó Francisco Asenjo Barbieri28, al copiarlas en la portada de la versión madrileña, fue producto del desconocimiento de la situación en que trabajó Guerrero. La inscripción decía: "Estos aires populares están transcritos con mucha incorrección pero yo los he copiado tales cuales vinieron del Perú". Hoy día, al contrario que Barbieri, pensamos que esta incorrección nos permite recomponer las piezas musicales partiendo de su 'esqueleto musical', e ir ensayando un perfil melódico y armónico que se asemeje a lo que realmente tocaron los músicos de ese tiempo, o incluso antes.

24 Guerrero, Juan Agustín, Yaravíes Quiteños, música ecuatoriana..., 3.

25 Guerrero, Juan Agustín, Catecismo Musical. Imprenta del Pueblo, Quito, 1857.

26 Ibid., prefacio.

27 Guerrero, Juan Agustín, Curso elemental de Música, Oficina tipográfica de F. Bermeo, Quito, 1875.

28 Un afamado compositor de zarzuelas, fue académico de Bellas Artes al crearse la Sección de Música en esta institución; más tarde fue miembro de la Real Academia Española. Emilio Casares, Rodicio, Francisco Asenjo Barbieri Asenjo, el hombre y el creador, Ediciones del ICCMU, Madrid, 1994. 


\section{El Documento}

Se trata de un manuscrito de 83 páginas que consta de dos partes, con 28 piezas musicales (Tabla 1). La primera correspondería, específicamente, a los 'Yaravíes quiteños'; la segunda consiste en una copia exacta del Códice Martínez Compañón 29 . Este último está formado por piezas de tipo festivo y religioso, como 'Cachúas y Tonadas', procedentes de Trujillo, Cajamarca, Guamachuco, Chachapoyas o Lambayeque, y lo habría adjuntado Jiménez de la Espada a los yaravíes enviados por Guerrero desde Quito; luego, todo habría sido copiado por Barbieri para ser presentado por Jiménez de la Espada como ponencia en el Cuarto Congreso de Americanistas, celebrado en Madrid en 1881: Yaravíes quiteños 30.

Si nos concentramos en la primera parte de este documento, encontramos muchas de las tradiciones de los pobladores originarios de Quito en piezas como: 'El masalla', 'ElAlbacito', 'El Llanto', 'Yupaishisca', 'El Yumbo', 'El Sanjuanito', melodías que formaban parte de sus repertorios ancestrales, al menos coloniales. En las partituras también aparecen informaciones de su uso, como por ejemplo en la del 'Yupaishisca', donde se explica: "Con este yaraví cantan los indios de las haciendas inmediatas a Quito, el Aldivino todos los días de fiesta a las tres de la mañana", sugiriéndonos que esta música trasciende lo musical y conforma el germen del hacer cotidiano de sus habitantes ${ }^{31}$.

Otras composiciones como 'El Mayordomo', 'La Bartola', 'Doña Lorenza', 'La Purificadora', 'La Parranda', 'La Robadora', o el '¡Alza que te han visto!', habrían sido afamadas y típicas de Quito y Guayaquil. Son músicas que invitan al que la escucha al disfrute, al baile y al canto32. Hay solo dos piezas con acompañamiento de texto: 'Otro Cuxnico' (quichua) y 'Amor fino' (castellano). En esta última, el texto presenta la 'picaresca quiteña', lo que se conoce hoy como 'sal quiteña':

Amor fino no seas tonto

aprende a tener vergüenza

29 El Códice del obispo Baltasar Martínez Compañón o Códice de Trujillo del Perú, sí contiene indicación exacta de la instrumentación. Original en la Biblioteca Real de Madrid. Los ejemplos musicales en el texto del obispo probablemente fueron escritos por Pedro José Solís, maestro de capilla de la Catedral de Trujillo de 1781 a 1823. Ver Stevenson, Robert, Music in Aztec and Inkas territory, University of California Press, 1968.

30 Actas del cuarto Congreso Internacional de Americanistas. Vol. 2: 162, I-LXXXIII. Madrid. 1881.

31 Los cronistas de los siglos XVI y XVII notaron que la música estaba vinculada estrictamente a cada ocasión, clasificando cada tipo como tono o tonada. Gruszczynska-Ziotkowska, Anna, El poder del sonido. El papel de las crónicas españolas en la etnomusicología andina, Ediciones Aya-Yala, Quito, 1995, 19.

32 Los cronistas indican una relación íntima entre el canto y el baile. Ibid., 21. 
al que te quiere, quiérelo

y al que no, no le hagas fuerza.

Qué bien dijo el aguardiente

cuando lo estaban bebiendo,

beberanme con cuidado

no vayan a estar cayendo.

\section{El Yaraví}

El yaraví es un género musical mestizo, que se cultivó en diferentes regiones del antiguo Virreinato del Perú en poblaciones como Quito, Arequipa, Cusco, Cajamarca, Alto Péru e incluso en el Río de la Plata. Sobre el término yaraví, Felipe Guamán Poma de Ayala, en su Crónica del Perú, lo denomina yaravi, explicándolo como un "canto de amor". Diego González Holguín lo anota como haráhuy, y lo describe como "música fúnebre"; Bernabé Cobo escribe arabí, dándole un significado de "música triste"33. El germen del yaraví sería el harawi incaico. En el Cusco, Anna Gruszczynska ${ }^{34}$ clasifica varios tipos de este género: harawi agrario, harawi épico, harawi trágico, harawi amoroso. En estos últimos, la música tenía mayor importancia que el texto35. Si era instrumental, tocaba el hombre la flauta; y si se cantaba, lo entonaba la mujer ${ }^{36}$. Los textos eran breves. Garcilaso decía: “... los versos amorosos hacían cortos por que fuessen más fáciles de tañer en la flauta"37, y citando una letra copiaba38:

Colla llapi

Puñunqui

Chaupituta

Samúsac

33 Entrada yaraví en Guerrero Gutiérrez, Pablo, Enciclopedia de la música ecuatoriana. Tomo II. CONMUSICA, Quito, 2004-2005, 1462 y ss.

34 Gruszczynska-Ziotkowska, Anna: El poder del sonido..., 89

35 Ibid., 89.

36 Ibid., 92.

37 De la Vega, Garcilaso, Primera parte de los comentarios reales, Pedro Crasbeeck, 1609, II, cap. XXVII, 87. Cit: Ibid., 90.

38 Ibid. 
También entendían que el sonido poseía un poder de cautivar, similar a la teoría de los afectos. Garcilaso narra la historia de una india del Cuzco, quien atrapada por la magia de la música dijo:

"... sábete que aquella flauta que oyes en aquel otero me llama con mucha passion y ternura, de manera que me fuerça a ir allá, Déxame, por tu vida, que no puedo dexar de ir allá, que el amor me lleva arrastrando para que yo sea su mujer y él mi marido"39.

El yaraví se apoyaría en la métrica de los textos, tanto profanos como religiosos, de los 'tonos hispánicos' del siglo XVII, en los que se intercalaban 'coplas' y 'estribillo'. Su cultivo y gran tradición hizo que se convirtiera en una forma popular muy conocida, haciendo que en 1865 Juan León Mera pidiera que se incluyera el término yaraví en el Diccionario de Autoridades, definiéndolo como un "... cantar dulce y melancólico"40. Además, calificaba al yaraví como una 'tonada'41, es decir, como un 'tono', más exactamente sería un 'tono triste'. El 'tono' era sinónimo de son y también equivalía al de 'tonada', especificando una música 'para sonar', con un baile y un texto en lengua vulgar ${ }^{42}$. A la vez, podemos relacionar 'tono' con la expresión 'tañer al tono de'43. Sebastián de Covarrubias definía 'tonada' como "el aire del cantarcillo vulgar, cuales son las tonadas que hoy usan los músicos de guitarra" 44 . Otras formas de llamar a las 'tonadas' o 'tonos' sería el de 'tañidos' o 'sones'45; y de forma más culta, 'ayres' $u$ 'obras'46. El término 'tono' aparece por primera vez nombrado en el Libro segundo de tonos y villancicos..., de Juan Arañés ${ }^{47}$. El 'tono' se adapta al modo de vida de sus lugareños, vistiéndose de la tradición de cada región. Honorato Vásquez comenta:

39 De la Vega, Garcilaso, Primera parte..., 90.

40 Guerrero Gutiérrez, Pablo, Enciclopedia..., 1463.

41 Ibid.

42 Valdivia Sevilla, Francisco, La guitarra rasgueada en España durante el siglo XVII, Servicio de Publicaciones y Divulgación Científica de la Universidad de Málaga. 2015, 107.

43 Ibid.

44 Ibid., 109.

45 Lo llama así Lucas Ruiz de Ribayaz, al compendio de piezas para guitarra, que integran la edición de Luz y Norte, Madrid, 1677.

46 Lo llama así Francisco Guerau, refiriéndose al compendio de piezas para guitarra que integran la edición del Poema Harmónico, Madrid, 1694.

47 Juan Arañés, Libro segundo de tonos y villancicos a una, dos, tres y cuatro voces, con la cifra de la guitarra española a la usanza romana. Roma, impresor Juan Bautista Robletti, 1624. Cit: Lambea, Mario. La música y la poesía en cancioneros polifónicos del siglo XVII (I): Libro de Tonos Humanos (1655-1656), Consejo Superior de investigaciones científicas. Institución “Milà i Fontanals”, Departamento de Musicología, Barcelona, 2000, 66. 
"...tono tiene que llamarse con genealogía lugareña, porque es una tonada o entonación especial...por acá los que hemos cantado tonos, con ellos hemos llorado y a ellos hemos acudido para alegrarnos..." 48

Por lo tanto, podemos definir 'tono' como una pieza musical de género menor y carácter popular profano, que sirve para acompañar un texto en lengua vulgar, con diferentes estructuras y modelos rítmicos y armónicos. En cambio, Anna Gruszczynska define el 'tono andino' "como un modelo melódico-rítmico, que desempeña la función de un signo simbólico en la transmisión social de la información". Estaría, así, por un lado la parte propiamente musical (melódicorítmico) y por otra la parte meta-musical (significativo) ${ }^{49}$.

En la provincia de Quito se cultivaron varios tonos, como el 'tono del costillar', el 'tono de prendas', el 'tono de la venada', el 'tono del ábago', el 'tono de chirimía', el 'tono de ambarcito', el 'tono de las vacas', el 'tono de oración o meditación', el 'tono triste' o yaraví, y finalmente el 'tono del niño' o villancico navideño, siendo tal su tradición que quedó la expresión popular entre los músicos de "tóquese un tono, maestro"50.

El 'tono del yaraví' es un 'tono' escrito en compás ternario (actualmente $3 / 4$ ) O compás binario (actualmente 6/8), conocido también como 'tono triste'. Antiguamente, parece ser que en su sección final se producía un cambio de tempo51, introduciéndose una 'tonada' o 'albazo', en tempo rápido, comúnmente llamada 'charada'52. Esto nos recuerda la sucesión (coplas-yaraví) (estribillocharada)53, usándose para su ejecución un instrumento de viento como el 'rondador', que ejecuta una melodía pentáfona (Fig. 2), combinado con un acompañamiento 'acórdico' ejecutado con la vihuela-guitarra, basados en la escala octatónica (Fig. 3).

48 Vázquez, Honorato, Reparos sobre nuestro lenguaje usual, Editorial Ecuatoriana, Quito, 1940. Entrada 'tono' o 'tonito', en: Guerrero Gutiérrez, Pablo, Enciclopedia..., 1363.

49 Gruszczynska-Ziotkowska, Anna: El poder del sonido, 21.

50 Entrada 'tono' o 'tonito' en: Guerrero Gutiérrez, Pablo, Enciclopedia..., 1362-1365.

51 Ibid., 1361.

52 Guzmán, Rafael María de, "El Yarabí o tono ecuatoriano", Álbum ecuatoriano. T. 1, N. 1, de enero. Quito. 1898, 6163. En: Entrada 'tono', en Guerrero Gutiérrez, Pablo, Enciclopedia..., 1364.

53 León Mera, Juan, Melodías indígenas. En: Entrada 'yaravi', en: Guerrero Gutiérrez, Pablo, Enciclopedia..., 1464. 


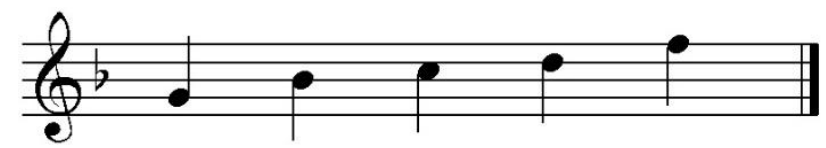

Figura 2 Escala pentatónica usada en la música de las culturas andinas.

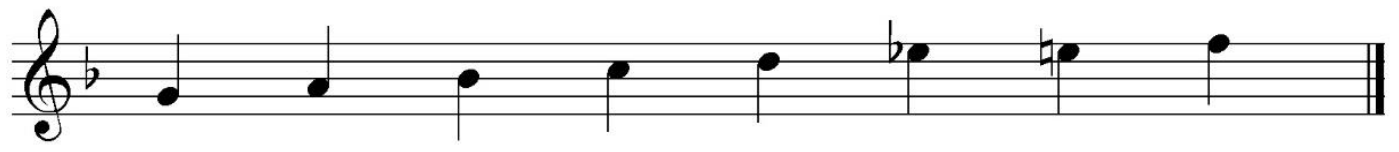

Figura 3 Escala octatónica, donde el "mi" puede ser bemol o natural, sucesión en que se fundamentan los acordes de la guitarra usados en la música andina.

La guitarra es símbolo en América del mestizaje, ya que no hay música de cualquier región suramericana que no utilice este instrumento. En Quito y la mayor parte de América, hasta el siglo XIX, se conocía a la guitarra como 'vihuela', y su popularidad radicaba en que se la tañía 'rasgueada', consistiendo su ejecución en colocar con la mano izquierda, en el mástil del instrumento, una serie de 'posiciones de acordes', y con la mano derecha se marcaba un ritmo o 'son', consiguiendo de esta manera realizar tanto la parte armónica como la rítmica de la música, y bastando simplemente con entonar un 'cantar', a la vez que se tañía, para producir música.

\section{Análisis musical}

Para el presente análisis vamos a revisar dos referencias musicales que nos van a guiar en el análisis de la estructura musical del yaraví: el 'tono triste de oración' y la melodía 'Salve, salve gran señora'.

El 'tono triste de oración' es un tipo de "yaraví religioso" 54 que consta de dos secciones: la primera, denominada 'pasacalle', está escrita en compás binario C, mientras que la segunda, llamada 'tono' está escrita sin indicación de compás55. Sin embargo, si observamos su notación musical, inmediatamente podemos asociarla con el compás ternario, utilizado en tiempos del barroco C3, llamado 'compás de

54 La obra fue encontrada por Pablo Guerrero en la ciudad de Cuenca (Ecuador) a principios de los años noventa. Se han ubicado cuatro piezas más de este tipo, también en la ciudad de Cuenca- Ecuador. Guerrero Gutiérrez, Pablo: "El Guamán o Tono de Oración". III Memorias. Proyecto Multinacional de Artes-O.E.A. Año III - no3 ECUADOR, Quito, 1993, 55.

55 Ibid. 
proporción menor'. En el 'pasacalle' vemos que se intercalan los acordes entre I-IIIIII6__ V7/5-I, siempre enfatizando de forma constante al III', y nunca aparece en el $V^{\circ}$ la 3era del acorde. Luego, en el 'tono' la melodía se ve acompañada por mucha figuración ornamental (lo que nos recuerda a la ejecución del rondador) e inicia con el $\mathrm{VI}{ }^{\circ}$ (lo que determina a esta sección), inmediatamente su segunda frase vuelve al III', realizando la resolución ya antes explicada (Fig. 4).
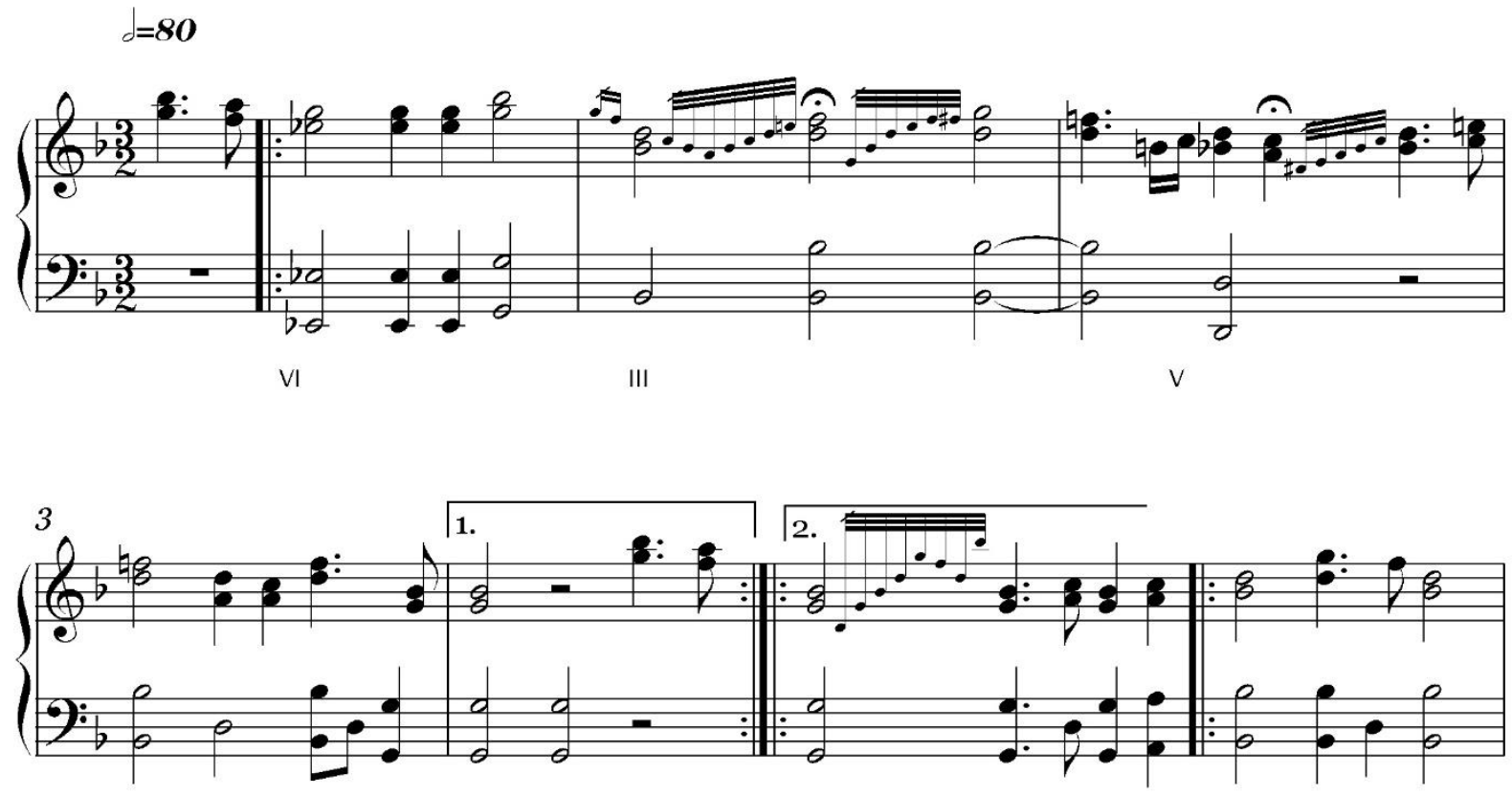

III V III

III

III

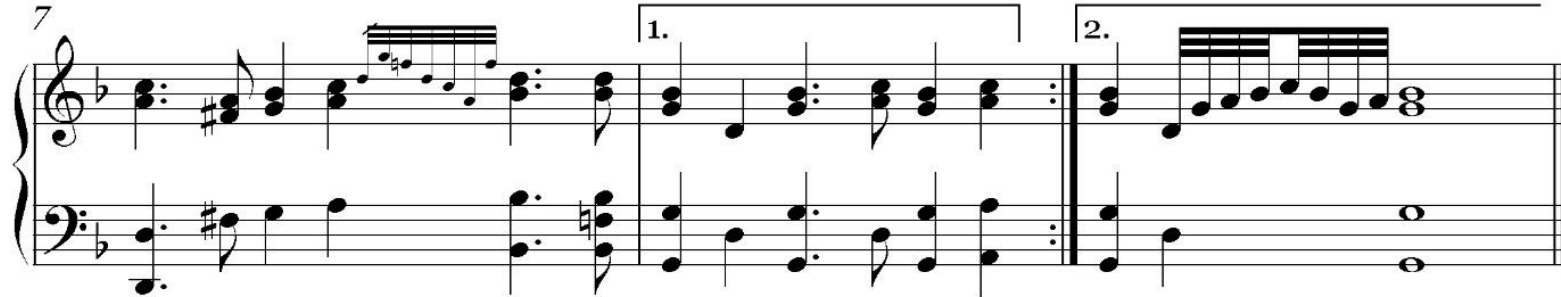

III

Figura 4 Reconstrucción de la segunda sección del Tono triste de oración.

En la melodía 'Salve, salve gran señora' hallamos, en cambio, como peculiaridad la llamada 'cadencia ecuatoriana', es decir, la resolución del ' $\mathrm{VI}{ }^{\circ}$ al $V^{\circ}$ menor'. Para Terry Pazmiño, la cadencia ecuatoriana sería típico de la música de 
Quito, no hallándose similar propiedad en el resto del continente americano ${ }^{56}$. Este tipo de movimiento armónico se llamó a partir del siglo XVI 'cadencia plagal'. Cayó en desuso a partir del siglo XVIII, pero sorprendentemente se mantuvo vigente en la música popular ecuatoriana (Fig. 5).

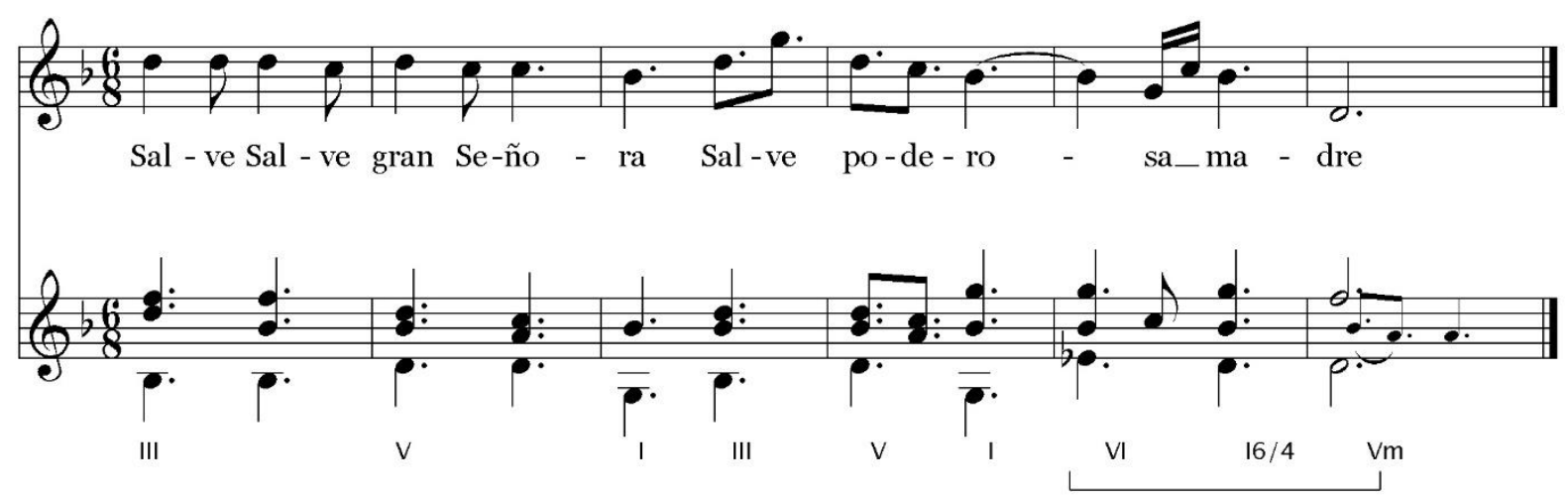

Figura 5 Armonización realizada por Terry Pazmiño de la melodía Salve, salve gran señora, para voz y guitarra.

El asiduo uso en el yaraví del $1 \mathrm{II}^{\circ}$ y de la cadencia plagal $\mathrm{VI}^{\circ}-\mathrm{Vm} \circ \mathrm{I}^{\circ}$ _ ${ }^{6 t a m a y o r}$ $\checkmark$, nos trasladan a tiempos del barroco. Pedro Cerone, en su El melopeo y maestro57 de 1613, nos habla acerca de las cláusulas más importantes del segundo tono, y aquí vemos que, durante el barroco, esta escala poseía dos cadencias principales: en la 'nota finalis' $I^{\circ}$, y en el $V^{\circ}$ (cadencia intermedia o suspensa). Seguido a estas se presentan las cadencias de paso: $\| I^{\circ}, I V^{\circ}$ y VII (Fig. 6).
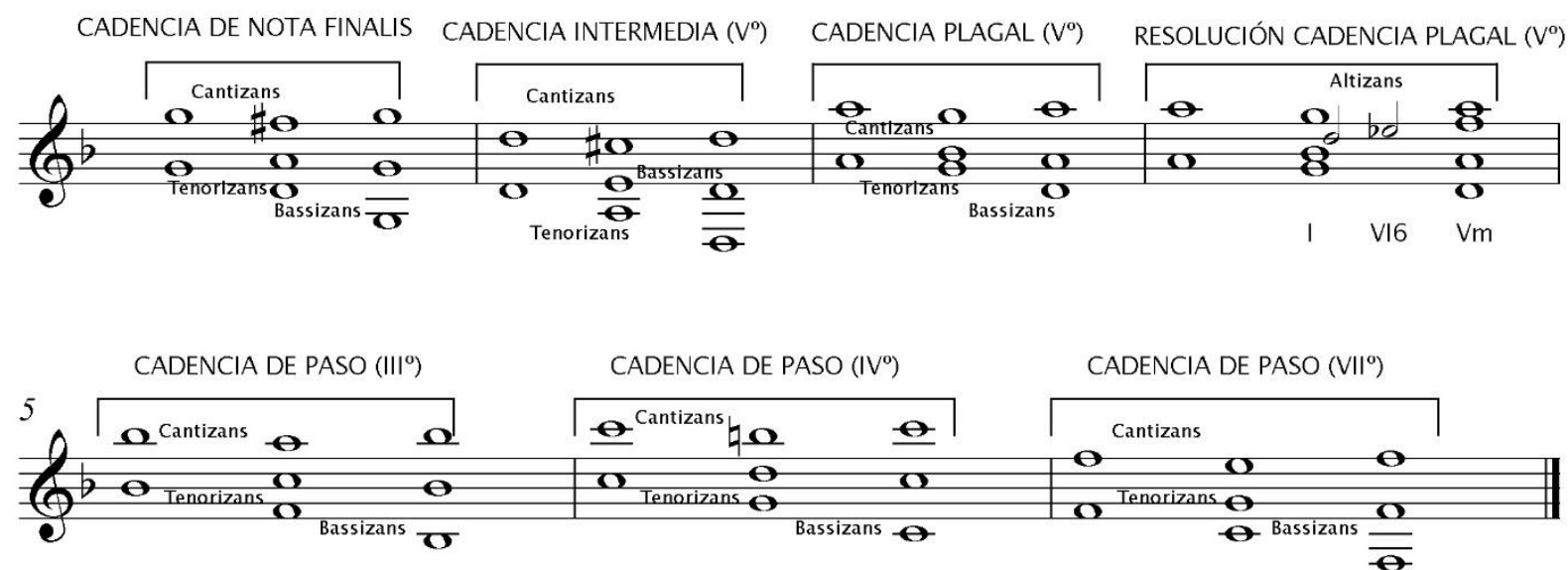

Figura 6 Clausulas del segundo tono (sol menor) y explicación del movimiento de sus voces.

56 Pazmiño, Terry, Recuperación del patrimonio musical intangible del Ecuador, Cuaderno Didáctico no 1. Editorial Pedro Jorge Vera de la CCE, Quito, sin año [2010 aprox], 11.

57 Cerone, Pedro, De la Mvsica Theorica Y Practica, Libro XVI, Nápoles, Giovanni Battista \& Lucrecio Nucci, 1613, f. 908. Ver: https://imslp.org/wiki/EI_melopeo_y_maestro_(Cerone,_Pietro) 
Esto nos invita a pensar que las características musicales del yaraví se conformaron en tiempos del barroco. Si observamos la melodía de 'El Albacito' (Fig. 7) vemos que para conseguir más variantes se aumentó a la escala una nota adicional, el $\mathrm{Vl}^{\circ}$ (mi) (Fig. 8). Esta adición permitió que se pudieran emplear las cadencias de paso del $I I^{\circ}$ y $\mathrm{VI} I^{\circ}$, peculiares del barroco. De igual forma, este $\mathrm{VI}{ }^{\circ}$ (mi) forzó a que se variase su VII ${ }^{\circ}$, añadiéndole un sostenido (\#) al mismo, y así logrando una cláusula final en el l’ (Fig.9). Veamos cómo podría haberse escrito esta pieza en notación barroca (Fig. 10).
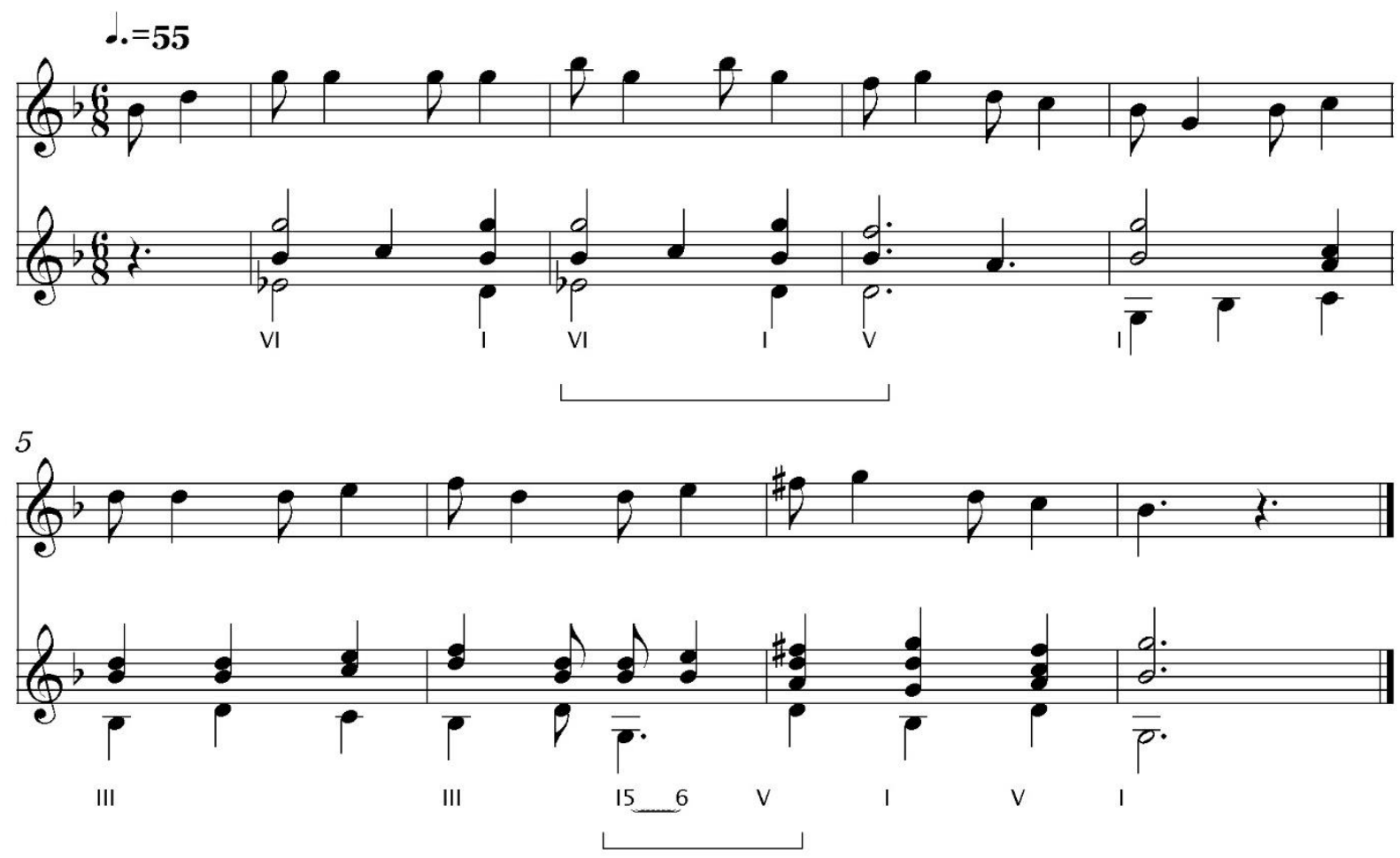

Figura 7 Armonización del yaraví El Albacito, de la colección de yaravíes quiteños, para flauta y guitarra.

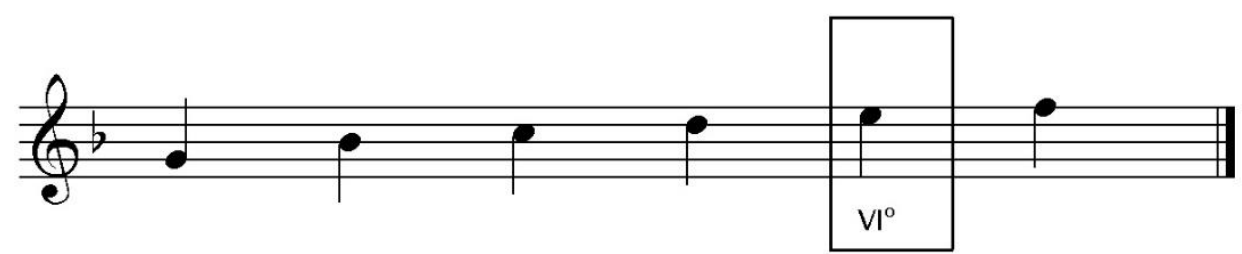

Figura 8 Escala pentatónica de Sol, con el $6^{\text {to }}$ grado añadido. 


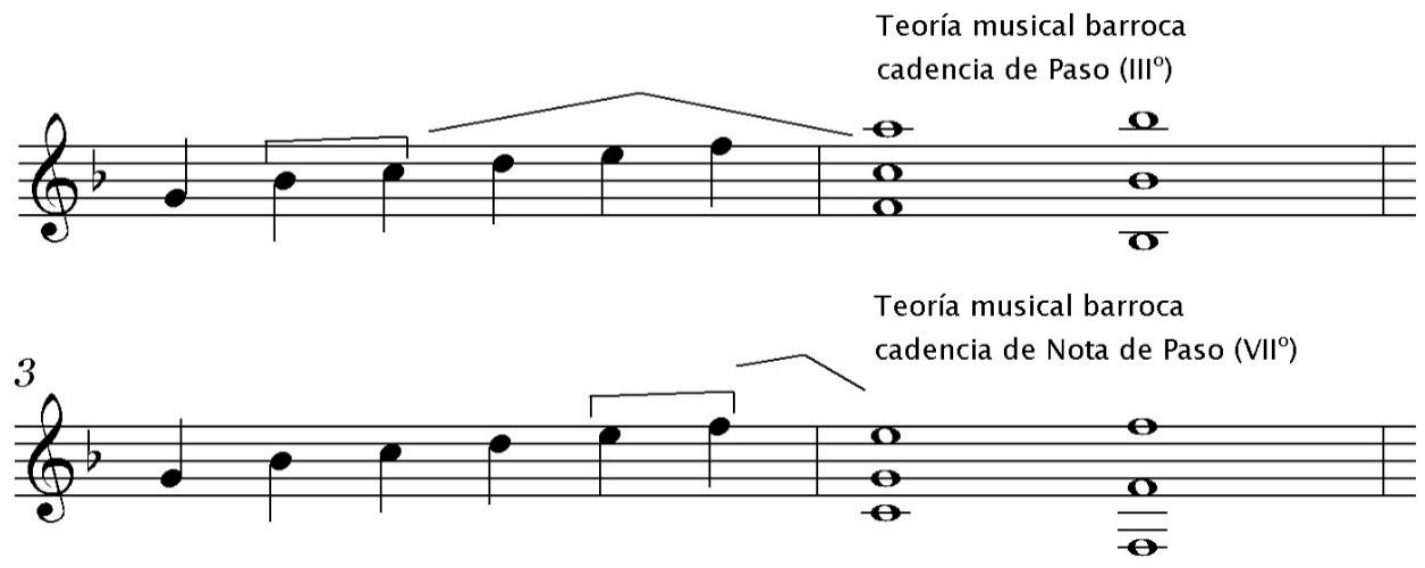

Teoría musical barroca

cadencia de Nota finalis $\left(I^{\circ}\right)$

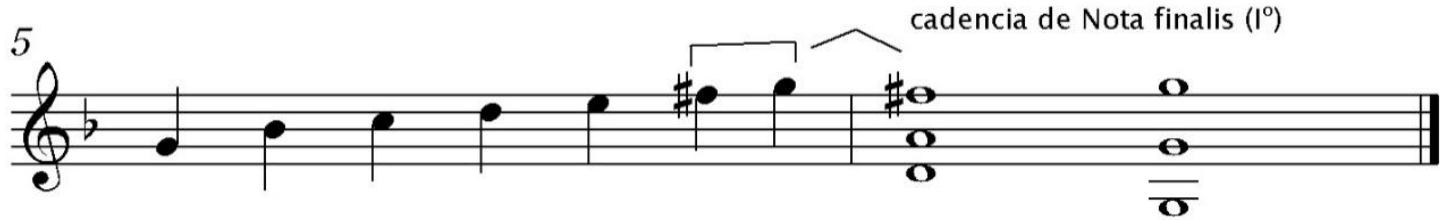

Figura 9 Ubicación de las cadencias barrocas en la escala hexatónica usada en El Albacito.
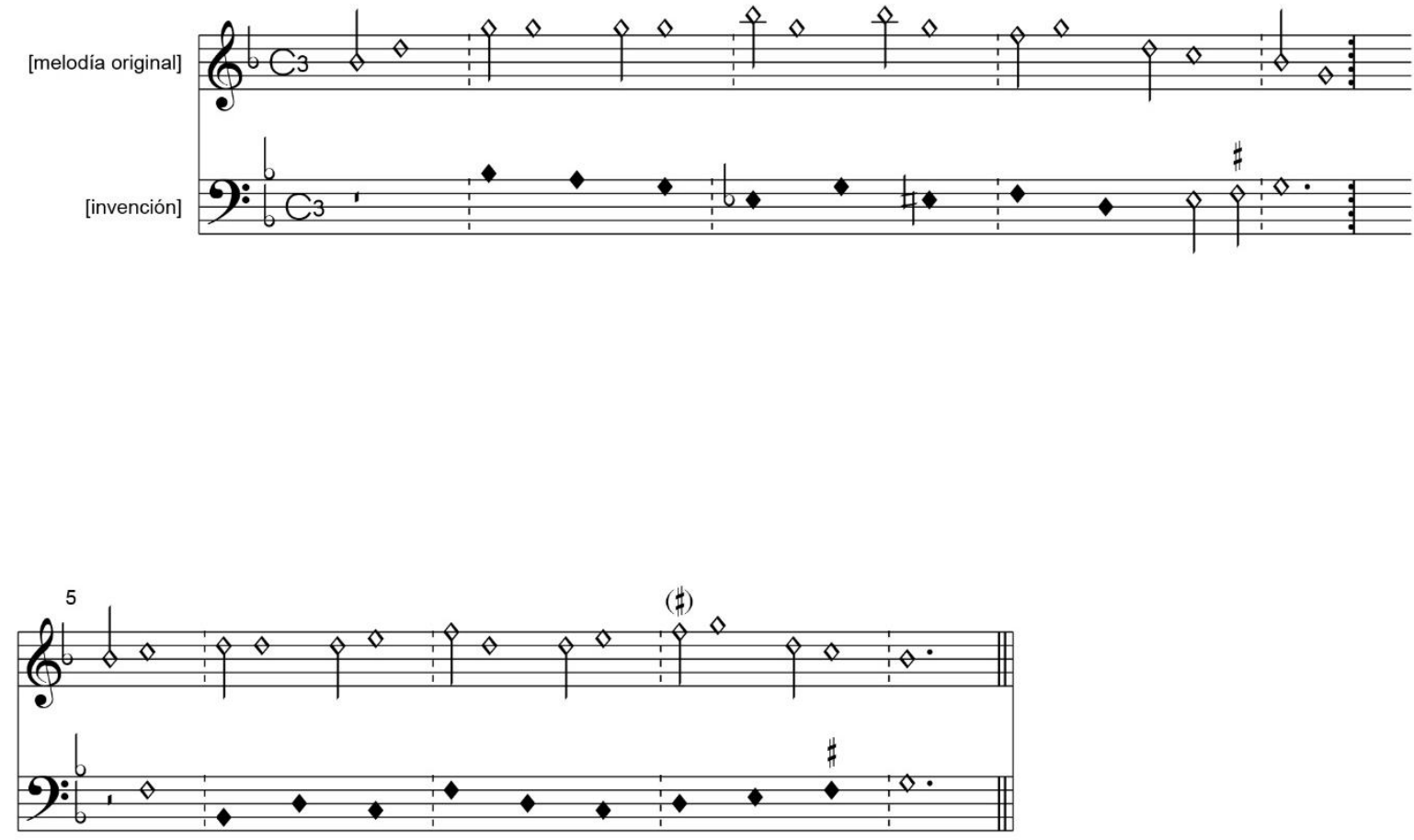

Figura 10 Versión barroca de El Albacito, para flauta y bajo contínuo. 


\section{Conclusiones}

Esta colección de piezas musicales constituye una pequeña muestra de la tradición musical de origen barroco-mestizo, de carácter popular, religioso y cotidiano de la provincia de Quito. Sus melodías pentatónicas, ejecutadas en el pífano, se ven vestidas por los acordes tañidos en la guitarra, acompañando a un texto que era una vía para 'contar anécdotas', memorias de penas o alegrías, dentro del 'tono triste'.

Adjuntamos a este estudio, como primer anexo, un catálogo pormenorizado de los Yaravíes Quiteños; y, como segundo anexo, los arreglos y adaptaciones, en versiones para guitarra, además de 'El Albacito', de: ‘¡Alza, alza que te han visto!', 'El Sanjuanito', 'La Bartola' y 'El Yapauchisca'.

A continuación, exponemos las distintas características halladas en las piezas examinadas:

1) Armonía pretonal. Tomando como referencia la relación que ofrece Cerone en su compendio El melopeo y el maestro, hemos podido hallar su tono y cadencias:

- '¡Alza, alza que te han visto!': 6to tono natural.

- 'El Albacito': 1er tono transportado.

- 'El Sanjuanito': 2do tono natural.

- 'La Bartola': 3er tono natural.

- 'El Yapauchisca': 1er tono natural.

2) La 'hemiola', característica típica de la música hispánica del Seiscientos, en la que se alterna el compás de 6/8 con el de 3/4, peculiaridad que pervive hasta hoy en España, por ejemplo en la 'bulería', y en Ecuador, en el ritmo de 'albazo'.

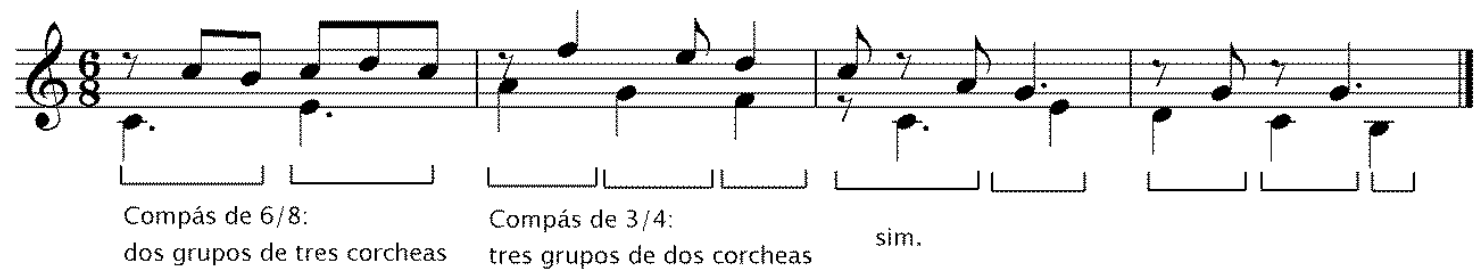

Figura 11 Frase inicial de la pieza iAlza, alza que te han visto! 
3) Melodía pentatónica o hexatónica, incorporando notas de paso, en especial el $\mathrm{VI}$.

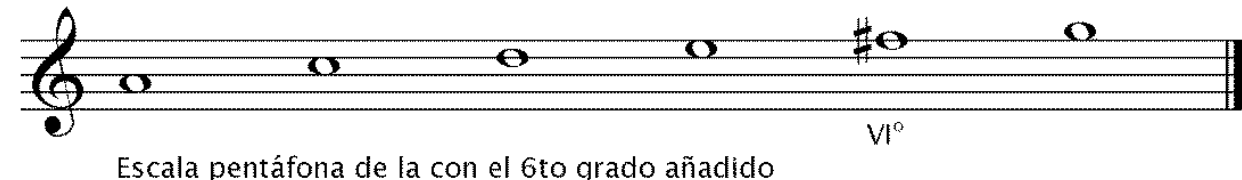

Figura 12 Escala pentatónica usada en El Sanjuanito

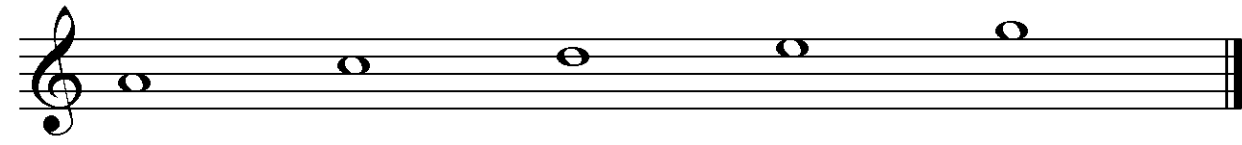

Figura 13 Escala pentatónica usada en La Bartola

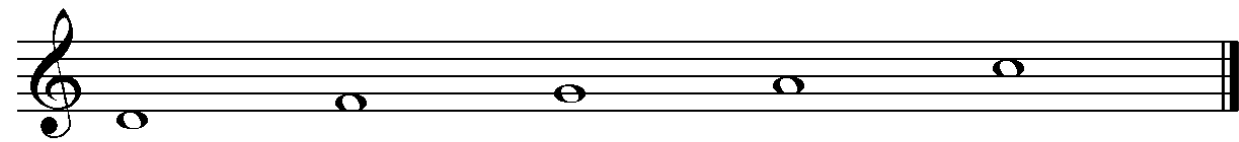

Escala pentáfona de Re

Figura 14 Escala pentatónica usada en El Yapauchisca

4) Presentan gran proximidad con danzas barrocas, como las jácaras, zarambeques, canarios, paisanos o guineos ${ }^{58}$. Adjuntamos el trozo inicial del tono de jácaras.

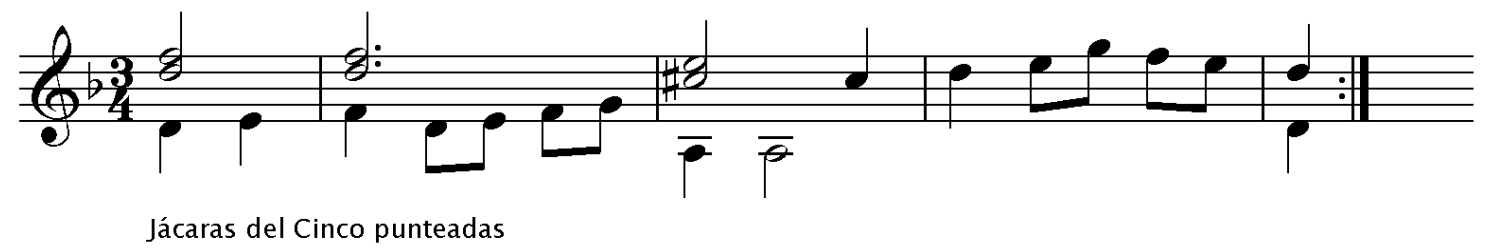

Figura 15 Jácaras del Cinco punteadas, del "Libro de diferentes cifras" M/811 (1705)

58 Una gran variedad de este tipo de danzas, en tablatura para guitarra barroca (de cinco órdenes), puede encontrarse en el Libro de diferentes cifras M/811 (1705). Francisco Alfonso Valdivia Sevilla (est.), Sociedad de la Vihuela, Madrid, 2008.

$59 \quad$ Ibid., 2. 
5) Su contenido musical, al poseer una o dos frases simétricas, permite el uso de 'disminuciones', al igual que otras danzas barrocas, pudiendo glosar la melodía con diferentes variaciones.
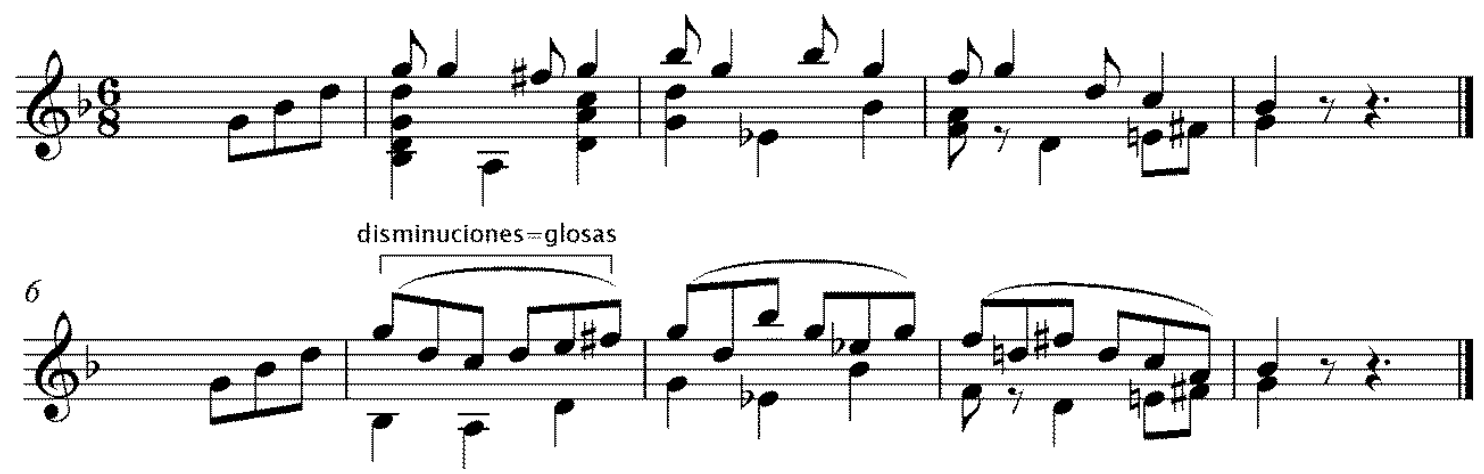

Figura 16 Frase inicial de El Albacito en el pentagrama superior, en el inferior vemos la misma melodía glosada

Gracias al interés mostrado por Marcos Jiménez de la Espada en redescubrir los tesoros americanos, y al trabajo recopilatorio de Juan Agustín Guerrero, conservamos hoy este manuscrito de yaravíes, que es una rica muestra de la música popular de la zona andina del Ecuador y en general de la región andina.

Fecha de recepción:

$01 / 12 / 19$

Aceptado para publicación: 


\section{Anexo}

\section{Tabla 1}

Catálogo descriptivo de los Yaravíes Quiteños, Madrid 1881.

\begin{tabular}{|c|c|c|}
\hline \multicolumn{3}{|c|}{ I Parte: Yaravíes Quiteños } \\
\hline Título & Compás/Armadura/Tono/Ins. & Apunte \\
\hline El Masalla & $\begin{array}{l}\text { 3:4 /\#/ mi menor (sin indicación) } \\
\text { [piano] }\end{array}$ & $\begin{array}{l}\text { Acostumbran cantando los indios en } \\
\text { sus casamientos, a manera de consejo } \\
\text { a sus hijos. }\end{array}$ \\
\hline El Albacito & $\begin{array}{l}6: 8 / \mathrm{b} \text { b/ sol menor }(\sin \\
\text { indicación) [piano] }\end{array}$ & $\begin{array}{l}\text { (Airoso) Con este despiertan los indios al } \\
\text { otro día de casados. }\end{array}$ \\
\hline El Llanto & $\begin{array}{l}\text { 6:8/ b b/ sol menor }(\sin \\
\text { indicación) [piano] }\end{array}$ & $\begin{array}{l}\text { (Lacrimoso) Que expresa naturalmente el } \\
\text { tono y sentimiento con que lloran las } \\
\text { indias. }\end{array}$ \\
\hline Yapaichisca & $\begin{array}{l}\text { 3:4/b/ re menor (sin indicación) } \\
\text { [piano] }\end{array}$ & $\begin{array}{l}\text { (Andante) Con este yaraví cantan los } \\
\text { indios de las haciendas inmediatas a } \\
\text { Quito, el Aldivino todos los días de fiesta a } \\
\text { las tres de la mañana. }\end{array}$ \\
\hline El Yumbo & $\begin{array}{l}\text { 6:8/ b/ re menor (sin indicación) } \\
\text { [piano] }\end{array}$ & $\begin{array}{l}\text { (Moderato) Antiguo yaraví que usan hasta } \\
\text { hoy los indios en eñ baile de los } \\
\text { Danzantes, tocado con el pito y } \\
\text { acompañamiento del tamboril. }\end{array}$ \\
\hline El San juanito & $\begin{array}{l}\text { 2:4 / /la menor (sin indicación) } \\
\text { [piano] }\end{array}$ & $\begin{array}{l}\text { (Allo) [Allegro] Baile de los indios de } \\
\text { Otavalo, que en los días de la festividad de } \\
\text { San Juan Bautista, lo usan cada año y con } \\
\text { mucha novedad tanto en Otavalo como en } \\
\text { los demás pueblos de la provincia de } \\
\text { Imbabura. }\end{array}$ \\
\hline El Mayordomo & $\begin{array}{l}2: 4 / \mathrm{b} / \text { re menor (sin indicación) } \\
\text { [piano] }\end{array}$ & Yaraví antiguo \\
\hline La Bartola & $\begin{array}{l}\text { 6:8 / /la menor (sin indicación) } \\
\text { [piano] }\end{array}$ & Yaraví antiguo \\
\hline Doña Lorenza & $\begin{array}{l}6: 8 \text { / b b b/ do menor }(\sin \\
\text { indicación) [piano] }\end{array}$ & $\begin{array}{l}\text { (Lamentabile) Yaraví antiguo, conservado } \\
\text { como una tradición de cierto suceso. }\end{array}$ \\
\hline Caliman-Ilugcixpa & $\begin{array}{l}\text { 6:8/b b/sol menor (sin indicación) } \\
\text { [piano] }\end{array}$ & (Espresivo) Yaraví antiguo. \\
\hline El Cuxnico & $\begin{array}{l}6: 8 / \mathrm{b} \quad \mathrm{b} \quad \mathrm{b} \quad \mathrm{b} / \mathrm{fa} \text { menor }(\sin \\
\text { indicación) [piano] }\end{array}$ & (Amoroso) Yaraví antiguo. \\
\hline Otro Cuxnico & $\begin{array}{l}6: 8 / \mathrm{b} \quad \mathrm{b} \quad \mathrm{b} \quad \mathrm{b} / \mathrm{fa} \text { menor }(\sin \\
\text { indicación) [voz, piano] }\end{array}$ & (Amoroso) Yaraví antiguo. \\
\hline Los Pastores & $\begin{array}{l}\text { 2:4/b/ re menor (sin indicación) } \\
\text { [piano] }\end{array}$ & Yaraví. \\
\hline
\end{tabular}




\begin{tabular}{|c|c|c|}
\hline Don Jacinto & $\begin{array}{l}6: 8 / b^{a} / \text { re menor (sin indicación) } \\
\text { [piano] }\end{array}$ & (Amoroso) Yaraví. \\
\hline Amor Mío & $\begin{array}{l}\text { 6:8/b/re menor (sin indicación) } \\
\text { [piano] }\end{array}$ & Yaraví popular \\
\hline Amor Fino & $\begin{array}{l}\text { 6:8/b/re menor (sin indicación) } \\
\text { [voz, piano] }\end{array}$ & Baile popular \\
\hline El Desengaño & $\begin{array}{l}\text { 6:8/b b/sol menor (sin indicación) } \\
\text { [piano] }\end{array}$ & (Espresivo) Yaraví \\
\hline Cuando me muera & $\begin{array}{l}3: 8 / \mathrm{b} / \mathrm{re} \text { menor (sin indicación) } \\
\text { [piano] }\end{array}$ & Yaraví. \\
\hline La Purificadora & 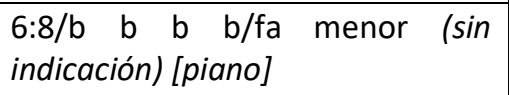 & $\left(\right.$ Mod $\left.^{\text {to }}\right)$ [Moderato] Yaraví. \\
\hline La Robadora & $\begin{array}{l}\text { 6:8/ /la menor (sin indicación) } \\
\text { [piano] }\end{array}$ & Yaraví. \\
\hline La Parranda & $\begin{array}{l}6: 8 / b \quad b \quad b \quad b / f a \text { menor }(\sin \\
\text { indicación) [piano] }\end{array}$ & Baile popular \\
\hline ¡Alza, que te han visto! & $\begin{array}{l}\text { 6:8/ /do mayor (sin indicación) } \\
\text { [piano] }\end{array}$ & Música de Guayaquil. \\
\hline $\begin{array}{l}\text { Baile de los Indios de } \\
\text { Quijos }\end{array}$ & $\begin{array}{l}\text { 6:8/ /do mayor (sin indicación) } \\
\text { [piano] }\end{array}$ & (Allo. ) [Allegro] \\
\hline \multicolumn{3}{|c|}{ II Parte: Cachúas, Tonadas y bailes de Huamachuco, Chachapoyas, Cazamarca, Lambayeque y Trujillo } \\
\hline Cáchua a duo y a cuatro & 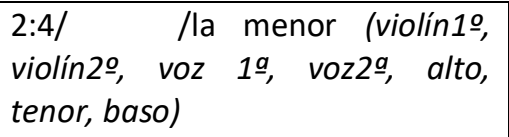 & ....al nacimiento de Cristo Nuestro señor. \\
\hline Cáchua & 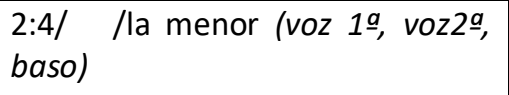 & Al Nacimiento de Cristo Nuestro Señor. \\
\hline Tonada "El Congo" & 3:8/\# \#/re mayor (voz, baso) & Para bailar cantando \\
\hline Baile del Chimo & C/\# \#/ re mayor (violín, baso) & \\
\hline Baile de Danzantes & 2:4 /\# \#/ [pífano, tamboril] & $\begin{array}{l}\text { Con pífano y tamboril. Se baila entre } \\
\text { cuatro u ocho o más con espadas en mano } \\
\text { o pañuelos, en forma de contradanza. }\end{array}$ \\
\hline Tonada del Chimo & $\begin{array}{l}\mathrm{C} / \# \text { \#/ si menor, (voz } 1 \stackrel{a}{ }, \text { voz } 2 \underline{a}, \\
\text { baso, tamboril) }\end{array}$ & Para bailar cantando \\
\hline Tonada “La Lata” & 3:8/ \#/mi menor (voz, baso) & Para bailar cantando \\
\hline Tonada "La Donosa" & 3:4/\# \# \#/re mayor (voz, baso) & Para bailar cantando. \\
\hline
\end{tabular}




\begin{tabular}{|c|c|c|}
\hline Tonada “El Conejo" & 3:8/ \# \#/ re mayor (voz, baso) & Para bailar cantando. \\
\hline $\begin{array}{l}\text { Tonadilla...llamase“El } \\
\text { Palomo" }\end{array}$ & 3:8/ \# \#/ re mayor (voz, baso) & $\begin{array}{l}\text { Del pueblo de Lambayeque, para cantar y } \\
\text { bailar. }\end{array}$ \\
\hline Lanchas & 3:8/ /la menor (voz, baso) & Para bailar. \\
\hline Tonada "El Diamante" & 2:4/\#/mi menor (violín, voz, baso) & De Caxamarca \\
\hline Tonada “El Huicho" & $\begin{array}{l}\text { 2:4/\# \#/re mayor (violín, voz, } \\
\text { baso) }\end{array}$ & De Chachapoyas \\
\hline Tonada Labrugita & 2:4/b /re menor (violín, voz, baso) & Para cantar de Guamachuco \\
\hline Cáchua "La Despedida" & $\begin{array}{l}\text { 2:4/\# \#/re mayor (violín, voz, } \\
\text { baso) }\end{array}$ & $\left(\mathrm{Mag}^{\text {so }}\right)$ [Magestuoso] de Guamachuco \\
\hline Tonada “El Auppamaro" & $\begin{array}{l}\text { 2:4/\#/mi menor (violín, voz, } \\
\text { basso) }\end{array}$ & (Adagio) De Caxamarca \\
\hline $\begin{array}{l}\text { Cáchua ...nombrada "El } \\
\text { Huicho" }\end{array}$ & $\begin{array}{l}\text { 3:8/ /la menor (sin indicación } \\
\text { instrumental)[voz y baso] }\end{array}$ & $\begin{array}{l}\text { Serranita...que cantaron } 8 \text { pallas del } \\
\text { pueblo de Otusco a N. Sra. Del Carmen de } \\
\text { la Ciudad }\end{array}$ \\
\hline $\begin{array}{l}\text { Cachuyta... "El buen } \\
\text { querer" }\end{array}$ & $\begin{array}{l}\text { 2:4/ /la menor (violín, voz, } \\
\text { basso) }\end{array}$ & ...de la montaña \\
\hline
\end{tabular}

a No era necesario el segundo bemol, sería un error del copista (Francisco Ásenjo Barbieri) o del recopilador (Juan Agustín Guerrero). 
Americanía. Revista de Estudios Latinoamericanos. Nueva Época (Sevilla), n. 10, p. 145-171, jul-dic, 2019

¡Alza, que te han visto!

Arreglo para guitarra: Francisco Xavier Calle

Manuscrito de Yaravíes Quiteños

Espresivo $\cdot=100$
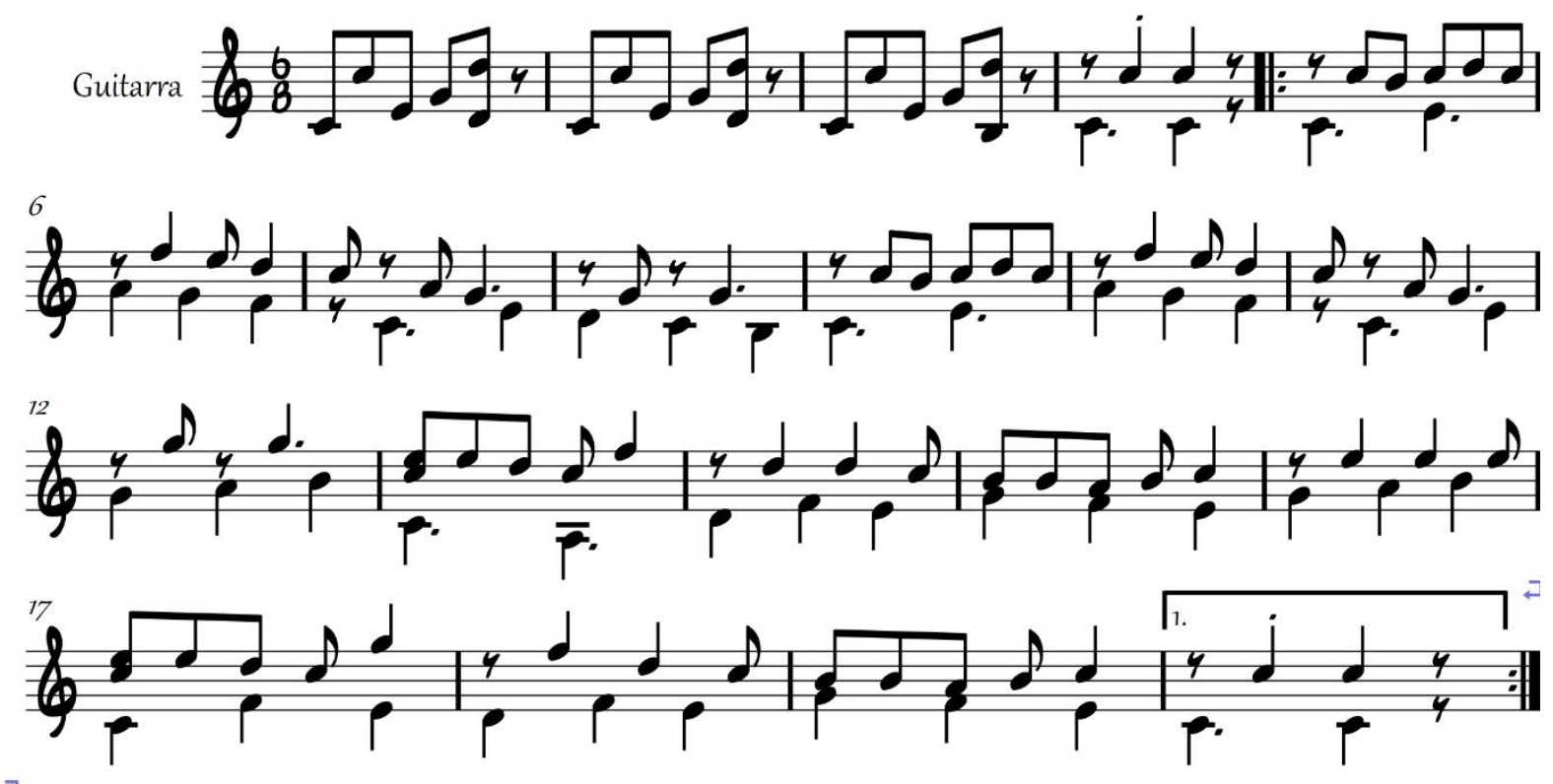

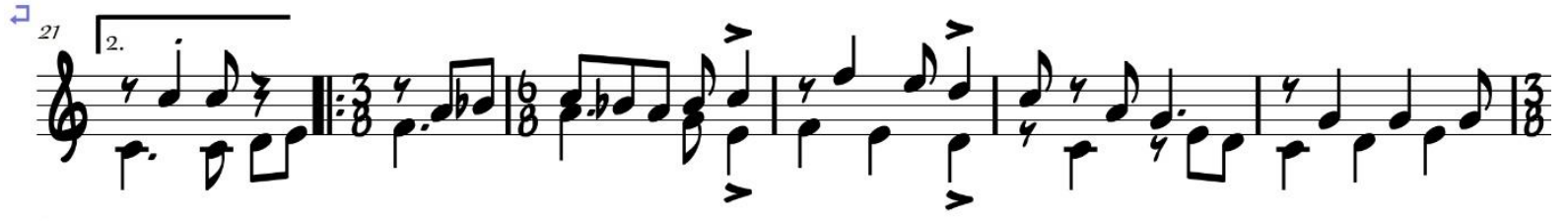
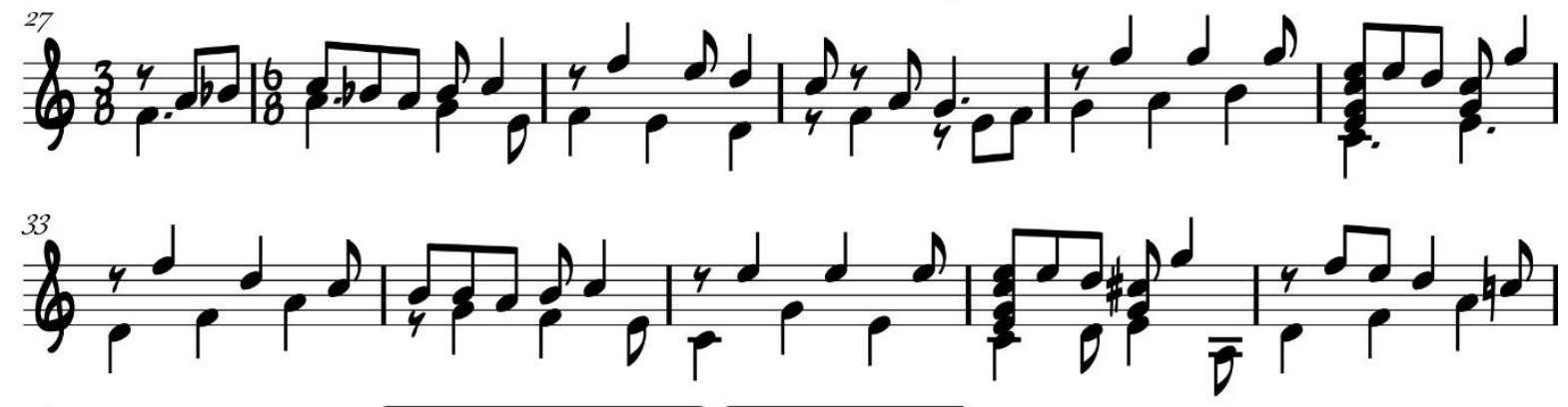

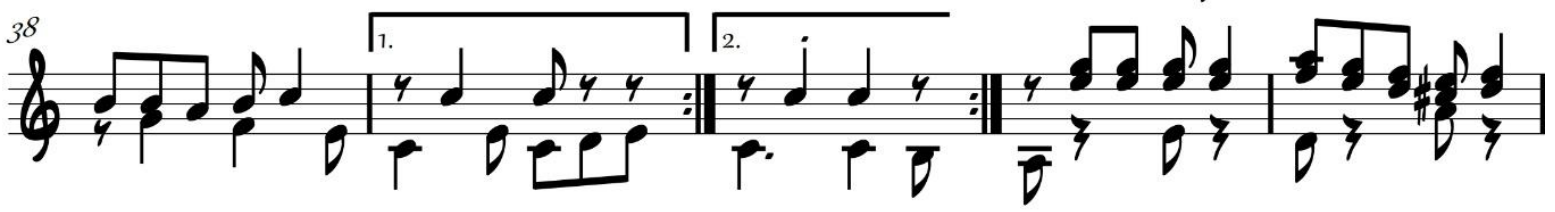
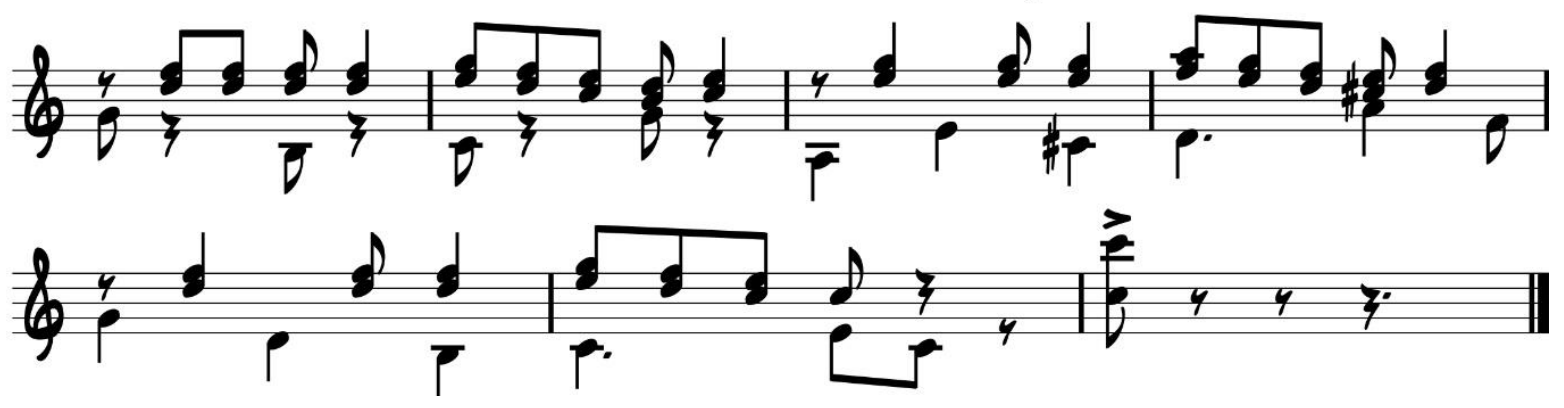

166 


\author{
El Albacito
}

Arreglo para guitarra: Francisco Xavier Calle

Manuscrito de Yaravíes Quiteños

Guitarra Airoso[-.=68]

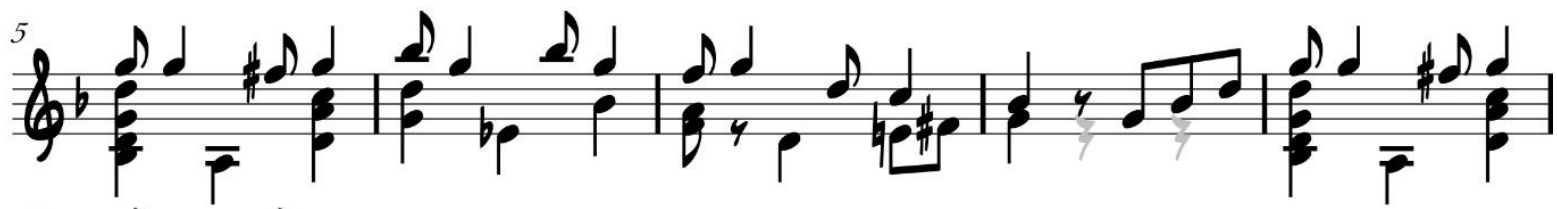

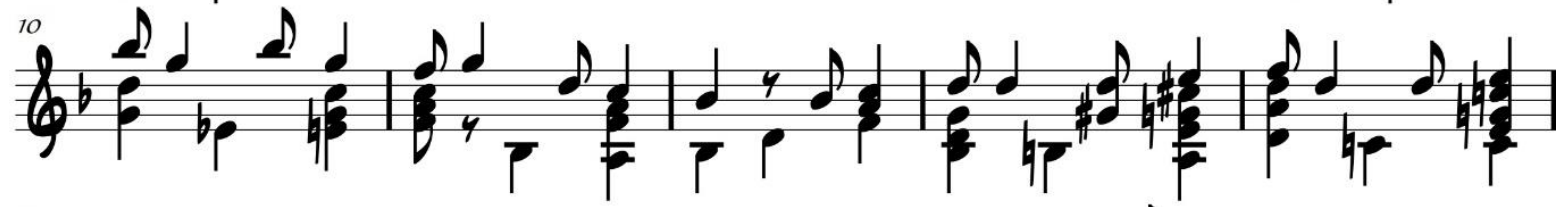

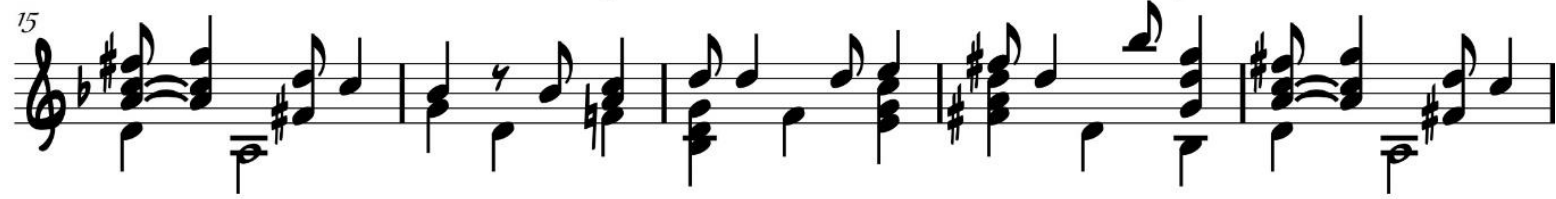

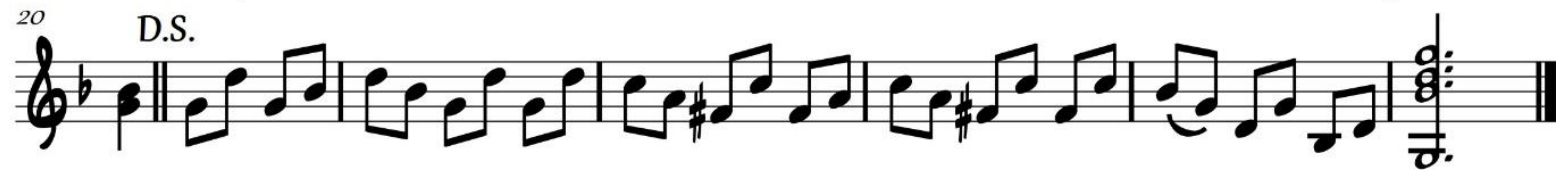




\section{El San Juanito}

Arreglo para guitarra: Francisco Xavier Calle

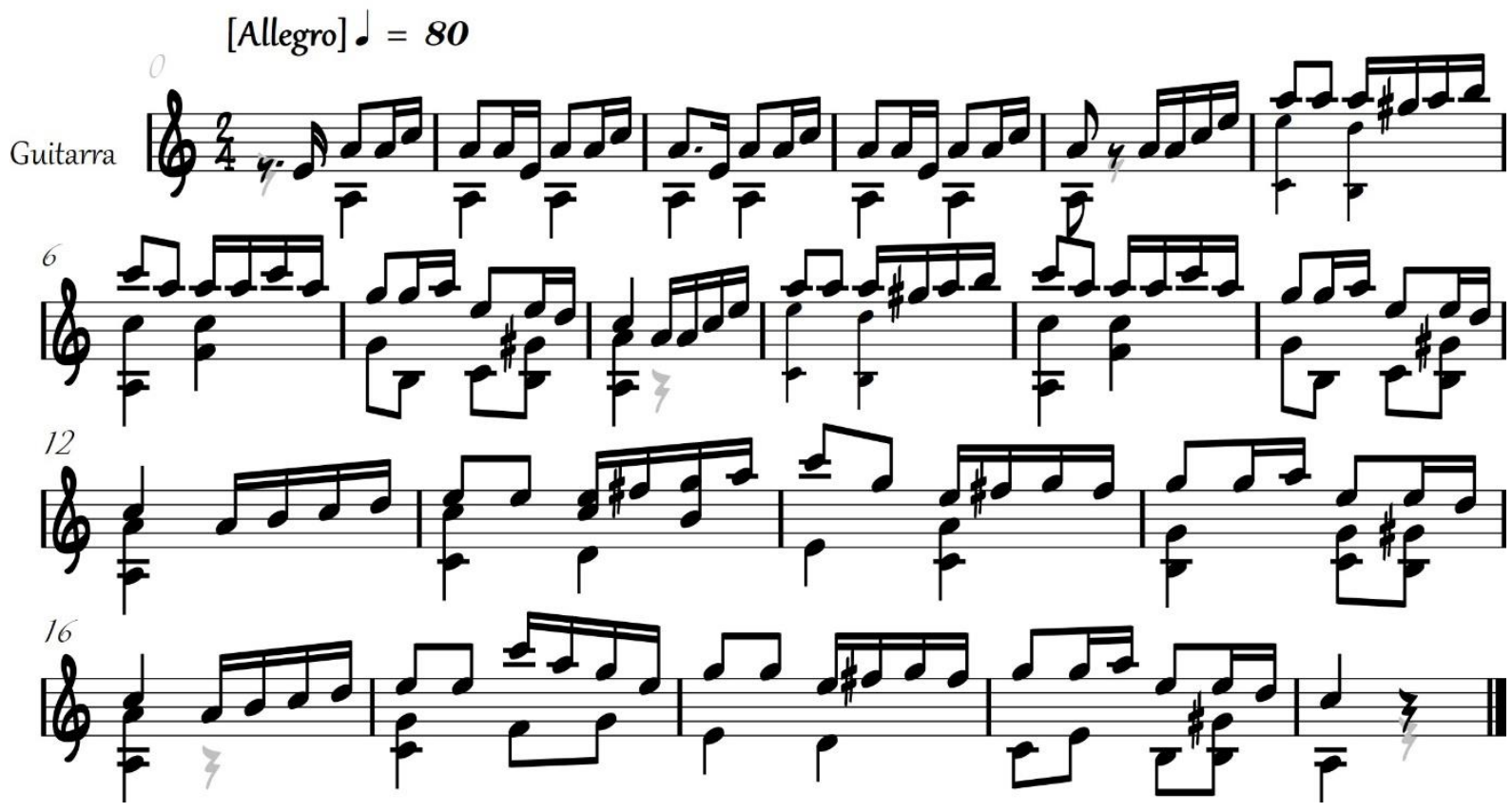


La Bartola

Manuscrito de Yaravíes Quiteños

Arreglo para guitarra: Francisco Xavier Calle
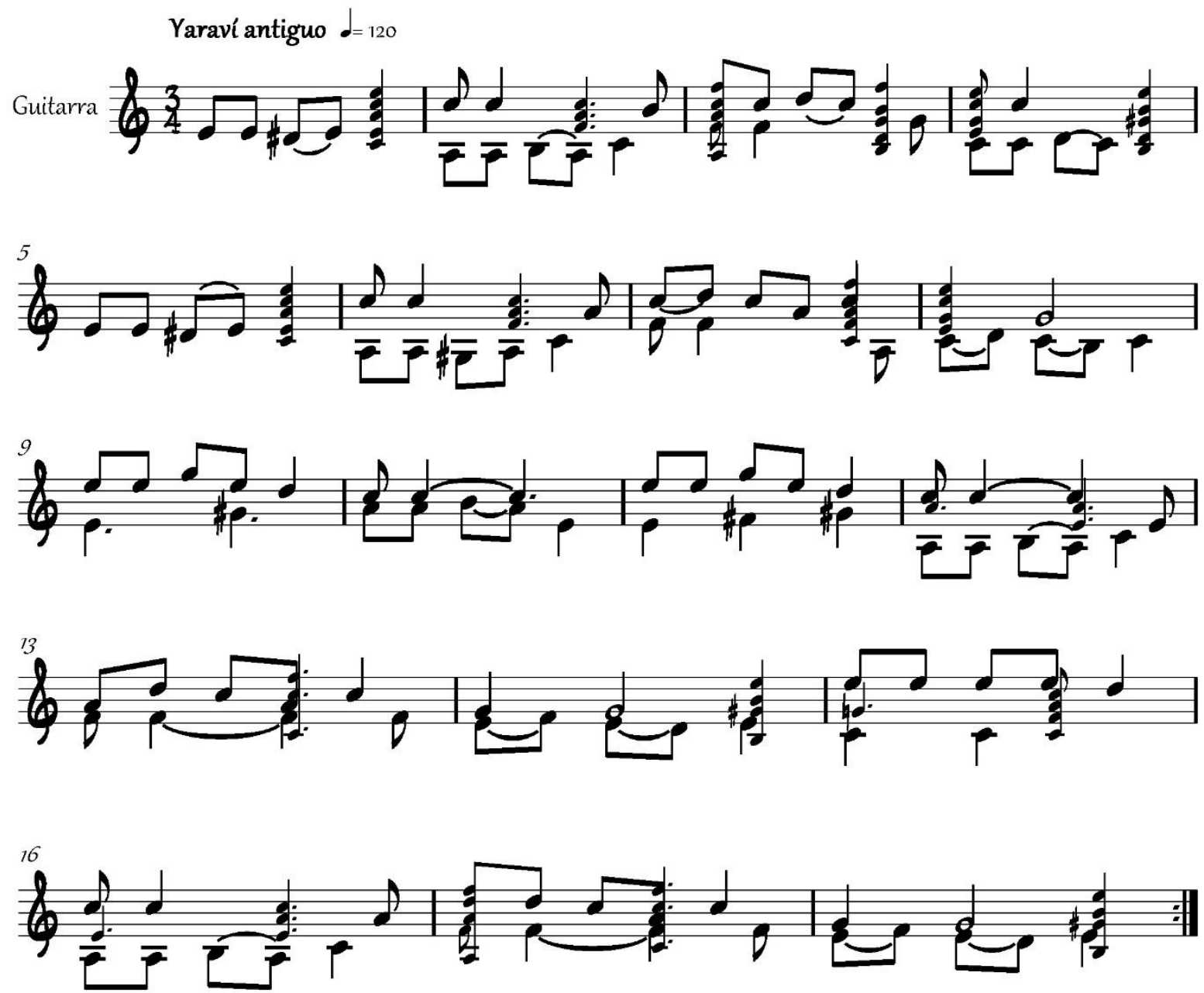


\section{El Yapaushisca}

Arreglo para guitarra: Francisco Xavier Calle
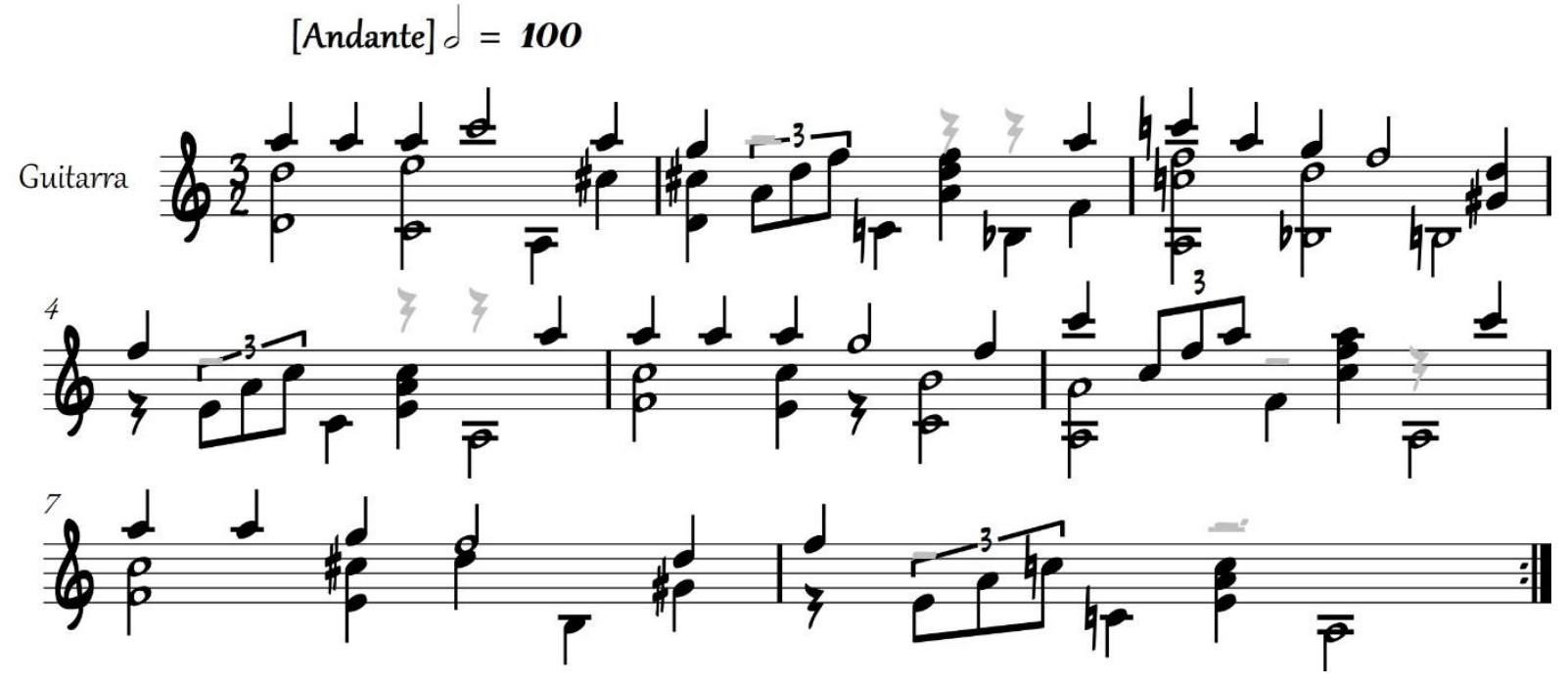


\section{Referencias Bibliográficas}

Cieza de León, Pedro de; Jiménez de la Espada, Marcos (pub.), Tercero Libro de las guerras civiles del Perú el cual se llama La Guerra de Quito, Imp. M. G. Hernández, Madrid, 1877.

De la Vega, Garcilaso, Primera parte de los comentarios reales, Pedro Crasbeeck, 1609.

Gruszczynska-Ziotkowska, Anna, El poder del sonido. El papel de las crónicas españolas en la etnomusicología andina, Ediciones Aya-Yala, Quito, 1995.

Guerrero, Juan Agustín, Catecismo Musical. Imprenta del Pueblo, Quito, 1857.

Guerrero, Juan Agustín, Curso elemental de Música, Oficina tipográfica de F. Bermeo, Quito, 1875.

Guerrero, Juan Agustín, Yaravíes Quiteños, música ecuatoriana del siglo XIX, Archivo sonoro del municipio de Quito, Quito, 1993.

Guerrero Gutiérrez, Pablo: "El Guamán o Tono de Oración". III Memorias. Proyecto Multinacional de Artes-O.E.A. Año III - n³ ECUADOR, Quito, 1993.

Guerrero Gutiérrez, Pablo, Enciclopedia de la música ecuatoriana. Tomo II. CONMUSICA, Quito, 2004-2005.

Jiménez de la Espada, Marcos, Noticias auténticas del famoso río Marañón, Imp. Real Academia de la Historia, Madrid, 1889.

Jiménez de la Espada, Marcos; Martínez, Francisco de Paula; Almagro, Manuel; Isern, Juan, El Gran Viaje, Ediciones Abya-Yala, Quito, 1998.

Lambea, Mario. La música y la poesía en cancioneros polifónicos del siglo XVII (I): Libro de Tonos Humanos (1655-1656), Consejo Superior de investigaciones científicas. Institución "Milà i Fontanals", Departamento de Musicología, Barcelona, 2000.

León Mera, Juan, Cantares del pueblo, Banco Central del Ecuador, Quito.

Palma, Ricardo, Tradiciones y artículos históricos, Imp. Torres Aguirre, Lima, 1899.

Pazmiño, Terry, Recuperación del patrimonio musical intangible del Ecuador, Cuaderno Didáctico $n^{\circ}$ 1. Editorial Pedro Jorge Vera de la CCE, Quito, sin año [2010 aprox].

Valdivia Sevilla, Francisco (est.), Libro de diferentes cifras M/81 1 (1705), Sociedad de la Vihuela, Madrid, 2008.

Valdivia Sevilla, Francisco, La guitarra rasgueada en España durante el siglo XVII, Servicio de Publicaciones y Divulgación Científica de la Universidad de Málaga. 2015. 